\title{
IMPACT OF A MULTIDISCIPLINARY DYSPHAGIA PROTOCOL IN THE STROKE UNIT
}

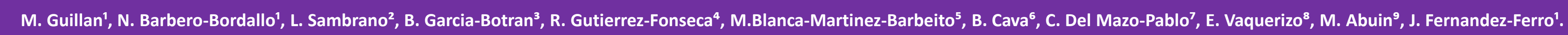

${ }^{1}$ Stroke Unit. Neurology. ${ }^{2}$ Swallow Rehabilitation. ${ }^{3}$ Dysphagia Unit Nursing. Otorhinolaryngology. ${ }^{4}$ Dysphagia Unit. Otorhinolaryngology. ${ }^{5}$ Endocrinology and Nutrition. ${ }^{6}$ Dietetic. ${ }^{7}$ Speech Therapy.

${ }^{8}$ Rehabilitation. ${ }^{9}$ Stroke Unit Nursing. Universitary Hospital Rey Juan Carlos, Madrid, Spain.

Introduction: Acute stroke is the most common cause of oropharyngeal dysphagia. It affects more than a third of stroke patients (37-78\%) and increases the risk of aspiration pneumonia (AP), the most frequent infectious complication in stroke patients (11-48\%). Until now, a lack of evidence prevented dysphagia screening to be recommended for the routine management of stroke. Following the latest systematic reviews, guidelines have incorporated it as a new recommendation. However, it is not yet clear what are the best tests or protocol for a routine dysphagia screening in the acute stroke context.

Our objective was to measure the impact of our dysphagia protocol in our stroke unit (SU).

Methods: We prospectively include all patients with stroke/TIA from September-2013 to March-2017 (protocol implemented in February-2014). Study periods: historic period(HP 9/2013-1/2014), initiation period (IP :2/2014-6/2014), consolidation period (CP:7/2014-3/2017). The stroke physician decides within the first 48-72 hours from admission if the dysphagia assessment may performed by a SU-nurse or by an specialised dysphagia-nurse; based on a low or high a priori risk of dysphagia respectively. A skilled nurse adapts the diet, establishes the need for complementary tests and monitors the patient throughout the whole admission. Dysphagia rehabilitation begins according to evolution. Adjusted odds ratios and $95 \% \mathrm{Cl}$ were obtained for AP diagnosis; in-hospital and 90-day mortality and 90-day independence rate (mRS $0-2)$. Pneumonia was defined as the presence of fever, typical respiratory symptoms, elevation of acute phase reactants and absence of another infectious focus, which may or may not be present on the chest radiograph, all after 48 hours of admission.

Results: 839 patients were included (age mean $71.3 \pm$ SD 13.4 (64;84)IQR): 80 HP/ 100 IP/ 659 CP. Baseline characteristics between groups were fairly comparable.

Adjusted regression analysis revealed that, compared to the HP: AP was 9.5 and 12.2 times lower in IP and CP respectively; independence rate was 5.7 and 4.8 times higher in IP and CP respectively; in-hospital mortality risk was reduced by $54 \%$ and $68 \%$ in IP and CP and 90 -day mortality was 3 times lower in $\mathrm{CP}$.

\begin{tabular}{|c|c|c|c|c|}
\hline $\begin{array}{c}\text { Baseline } \\
\text { characteristics } \\
\mathbf{N}=\mathbf{8 3 9}\end{array}$ & $\begin{array}{c}\text { Historic Period } \\
\text { N } 80 \\
\text { Sep 2013- Jan } 2014\end{array}$ & $\begin{array}{l}\text { Initiation Period } \\
\text { N } 100 \\
\text { Feb } 2014-\text { Jun } \\
2014\end{array}$ & \begin{tabular}{|c} 
Consolidation \\
Period \\
N 659 \\
Jul 2014- Feb 2017
\end{tabular} & $p<0.05$ \\
\hline $\begin{array}{l}\text { Age (years) } \\
\text { mean } \pm D S\end{array}$ & $73.3 \pm 13.8$ & $72.9 \pm 13.8$ & $70.8 \pm 13.4$ & ns \\
\hline Sex Female $\quad N(\%)$ & 39 (48.8\%) & $40(40 \%)$ & 295 (44.8\%) & ns \\
\hline Hypertension $\mathrm{N}(\%)$ & $53(66.3 \%)$ & $80(80 \%)$ & $442(67 \%)$ & ns \\
\hline Diabetes & $18(22.5 \%)$ & $35(35 \%)$ & $185(28 \%)$ & ns \\
\hline Dyslipemia $\quad N(\%)$ & $36(45 \%)$ & $48(48 \%)$ & 321 (48.7\%) & ns \\
\hline Smoking habit N(\%) & $14(17.5 \%)$ & $17(17 \%)$ & $152(23 \%)$ & ns \\
\hline $\begin{array}{l}\text { Baseline NIHSS } \\
\text { median (IQR) }\end{array}$ & $8.3(2 ; 13)$ & $6.7(1 ; 11)$ & $6.8(1 ; 10)$ & ns \\
\hline Ischemic stroke $N(\%)$ & $66(82.5 \%)$ & $87(87 \%)$ & $572(86.8 \%)$ & ns \\
\hline TIA $N(\%)$ & $8(10 \%)$ & $14(14 \%)$ & 127 (19\%) & 0.043 \\
\hline $\begin{array}{l}\text { Lesion location: } \\
\text { Right hemisphere } \\
\text { N\% }\end{array}$ & $44(55 \%)$ & $58(58 \%)$ & 350 (53\%) & ns \\
\hline Infratentorial N\% & 9 (11.3\%) & $19(19 \%)$ & $106(16 \%)$ & ns \\
\hline $\begin{array}{l}\text { Reperfusion } \\
\text { therapies IVT or/plus } \\
\text { MT N\% }\end{array}$ & $3(3.8 \%)$ & $4(4 \%)$ & $88(13.4 \%)$ & 0.014 \\
\hline
\end{tabular}
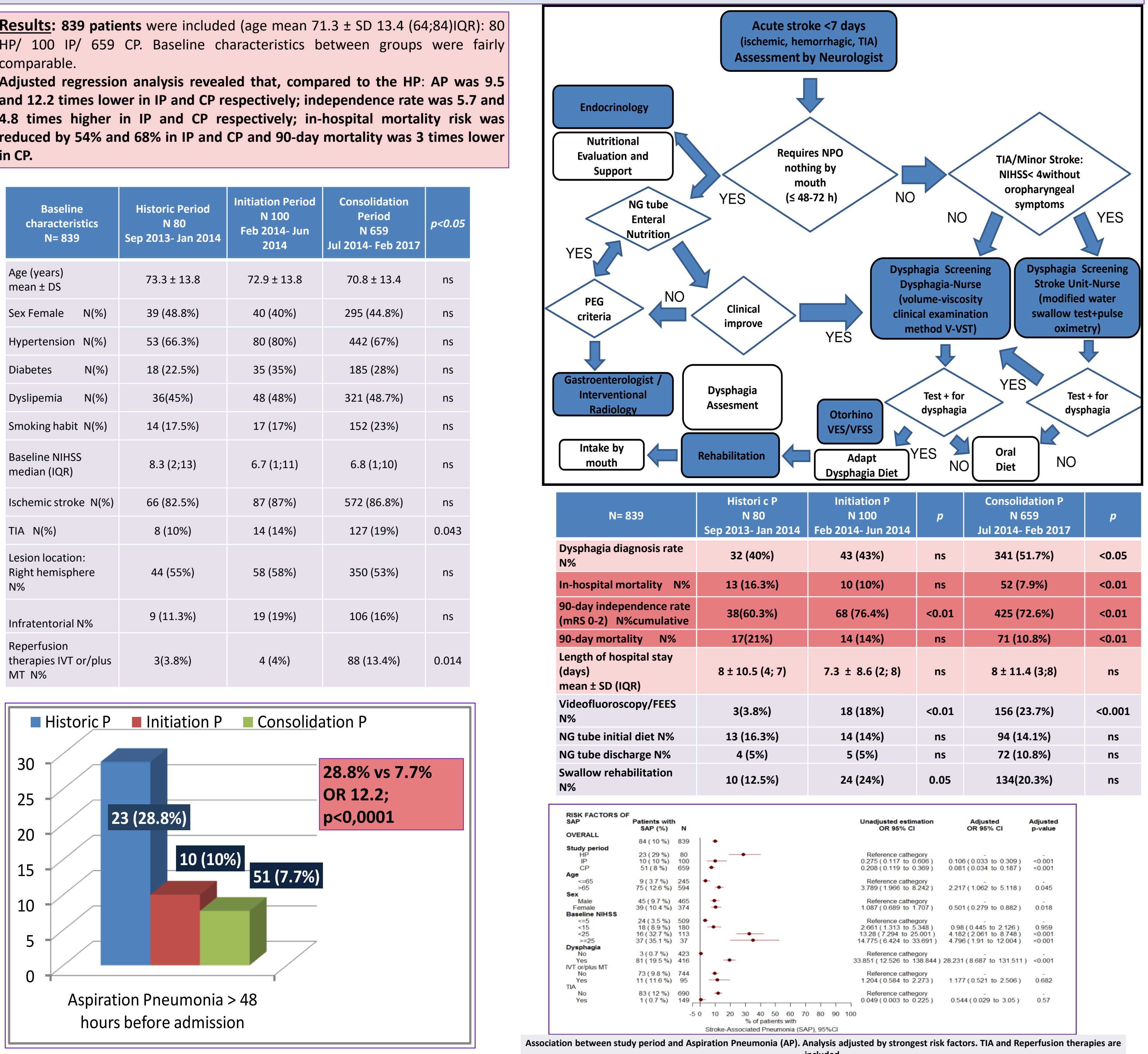

included.

Conclusions: Our dysphagia protocol was associated with a lower risk of AP, lower hospital and 90-day mortality and a higher probability of independence at day 90 . The reduction in mortality risk was largely associated with lower AP occurrence. 